\title{
Smoothing additive manufactured parts using ns-pulsed laser radiation
}

\author{
Florian Kuisat $^{1}\left[\right.$ Fernando Lasagni $^{2} \cdot$ Andrés Fabián Lasagni $^{1,3}$
}

Received: 17 August 2020 / Accepted: 19 January 2021 / Published online: 9 February 2021

(c) The Author(s) 2021

\begin{abstract}
It is well known that the surface topography of a part can affect its mechanical performance, which is typical in additive manufacturing. In this context, we report about the surface modification of additive manufactured components made of Titanium 64 (Ti64) and Scalmalloy ${ }^{\circledR}$, using a pulsed laser, with the aim of reducing their surface roughness. In our experiments, a nanosecond-pulsed infrared laser source with variable pulse durations between 8 and $200 \mathrm{~ns}$ was applied. The impact of varying a large number of parameters on the surface quality of the smoothed areas was investigated. The results demonstrated a reduction of surface roughness $S a$ by more than $80 \%$ for Titanium 64 and by $65 \%$ for Scalmalloy ${ }^{\circledR}$ samples. This allows to extend the applicability of additive manufactured components beyond the current state of the art and break new ground for the application in various industrial applications such as in aerospace.
\end{abstract}

Keywords Direct laser smoothing $\cdot$ Nanosecond-pulsed laser source $\cdot$ Surface modification $\cdot$ Additive manufacturing components $\cdot$ Scalmalloy ${ }^{\circledR} \cdot$ Ti64

\section{Introduction}

Additive manufacturing (AM) processes are becoming more and more important for industrial applications because complex parts can be easily manufactured. A wide range of materials can be used for AM processes. Common metals are Ti64 and Scalmalloy ${ }^{\circledR}$. Due to their low weight and excellent strength properties, both materials are excellent materials for a wide range of applications, such as in the aerospace industry $[1,2]$. The AM components are fabricated layer by layer from three-dimensional models, as opposed to traditional subtractive fabrication technologies. Numerous technologies such as Powder Bed Fusion (PBF) or Direct Energy Deposition (DED) exist for this purpose. Most of these technologies

Florian Kuisat

florian.kuisat@tu-dresden.de

1 Institute for Manufacturing Technology, Technische Universität Dresden, George-Baehr-Str. 3c, 01069 Dresden, Germany

2 CATEC Advanced Center for Aerospace Technologies, C/Wilbur y Orville Wright 19, La Rinconada, 41309 Seville, Spain

3 Fraunhofer-Institut für Werkstoff- und Strahltechnik IWS, Winterbergstr. 28, 01277 Dresden, Germany have in common that the powder particles are locally melted and solidified [3]. In the case of PBF process, a laser or electron beam scans and melts the powder layer to create the component. Due to the nature of the fabrication process, the manufactured parts have a relatively high roughness level on their surface, typically between 8 and $30 \mu \mathrm{m}$ (Ra) for Laser PBF, which in some cases reduces their fatigue behavior and mechanical performance [4]. For instance, Sakar et al. demonstrated an improvement in fatigue life of laser-treated AM components of more than 100\% compared to its as-built counterpart [5]. Other researchers have also shown enhancement of the stress resistance caused by surface post-treatment processes [6, 7]. This means that this is an extremely important characteristic of the surface quality, which is relevant to improve the technical capacities of these components such as fatigue lifetime $[8,9]$.

To improve the surface quality of AM parts, further production steps are frequently necessary [10]. Therefore, the roughness has to be decreased by means of a surface finishing process. Common surface finishing techniques are milling, blasting and vibration grinding $[4,11,12]$. However, the limited ability to treat complex shapes and geometries is often a challenge for these technologies [13, 14].

Another flexible post-processing technology for improving the quality of the 3D-manufactured parts consists of 
using laser surface treatments. Laser polishing has become a significant importance in the last 10 years and has several advantages against conventional polishing techniques [15-18]. For example, laser-based methods work without employing mechanical forces and deformations and make it possible to polish complex three-dimensional geometries or workpieces with thin materials [19]. Due to the characteristic of the laser treatment process, the surface morphology can be changed based on re-melting, without the addition of polishing agents, chemicals or grinding materials [20].

Many ongoing research works concentrate on laser-based surface smoothing techniques. Mainly, continuous wave operating laser sources $(\mathrm{cw})$ are used for macro-applications with remelting depths up to $200 \mu \mathrm{m}$. In contrast, pulsed laser sources (pw) are generally used for micro polishing with remelting depths of several micrometers [21]. Lambarri et al. investigated the laser surface smoothing process of nickelbased alloys and were able to show a reduction in roughness as a function of the scanning speed and laser power using $\mathrm{cw}$ laser radiation [22]. Similarly, Marimuthu et al. have examined that cw laser polishing of SLM components can be an effective way to improve the surface quality in Ti-6Al-4 V [23]. Pulsed laser radiation is partially used for micro polishing processes where the beam irradiates the material with laser pulses at a fluence level that causes surface melting and ablation. For example, Perry et al. showed a reduction of the average surface roughness Ra from 0.206 to $0.070 \mu \mathrm{m}$ using a Nd:YAG laser source with $650 \mathrm{~ns}$ long pulses [24]. Also, Chow et al. have indicated that the surface quality can be improved by adjustment of the focal offset position of the laser radiation [25]. Many other research studies concerning laser polishing have been published by Propawe and other researchers [26-29], reporting that the quality of the smoothing process can be controlled by diverse parameters such as the pulse duration, the laser power or the focal position. In addition, the quality of the smoothed surface depends on the base material and the initial surface topography and roughness. The reached results up to now have shown that laser smoothing can be used to successfully compete with conventional polishing processes. However, only a few publications are available on laser smoothing of the innovative additive manufactured Scalmalloy ${ }^{\circledR}$ or Titanium 64 substrates [16, 23-25, 30], defining the main objective of the present research. In particular, the use of an industrial laser system providing pulses in the nanosecond range for the post-treatment process of AM materials has not been sufficiently researched.

This work examines the utilization of nanosecond pulsed laser smoothing as innovative method to improve the surface quality of additive manufactured parts of Scalmalloy ${ }^{\circledR}$ and Titanium 64. An important aspect of the investigation is to determine the achievable surface roughness levels. The experiments are conducted using a nanosecond-pulsed infrared laser source with variable pulse durations between 8 and 200 ns was applied. The topography of the treated samples is investigated using confocal microscopy as well as scanning electron microscopy.

\section{Experimental procedure}

\subsection{Materials}

Specimens of Ti6Al4V, also known as Titanium 64 (Ti64), and Scalmalloy ${ }^{\circledR}(\mathrm{Al}-\mathrm{Mg}-\mathrm{Sc})$ were used in this study. The samples were produced by laser-Powder Bed Fusion which belongs to the category of additive manufacturing processes. This technology brings the best resolution and accuracy of current metal AM methods. These materials are characterized by high strength and high ductility combined with lightweight and are today the most used additively manufactured alloys for aerospace components [31, 32].

Ti6Al4V and Scalmalloy ${ }^{\circledR}$ used powders were supplied by Renishaw and TOYAL Europe, respectively. The chemical composition of the main alloying elements for the $\mathrm{Al}-\mathrm{Mg}-\mathrm{Sc}$ alloy used in this study ranged from $4.5-4.9 \mathrm{Mg}$, 0.68-0.80 Sc, 0.2-0.4 $\mathrm{Zr}$ and 0.2-0.7 Mn (all compositions in wt $\%$ ). More detailed information can be found in [1]. The particle size distribution for this alloy was $\mathrm{D} 10=30.6 \mu \mathrm{m}$, $\mathrm{D} 50=48.0 \mu \mathrm{m}, \mathrm{D} 90=69.1 \mu \mathrm{m}$ with an average particle size of $51.0 \mu \mathrm{m}$. Particles were mostly spherical, with circularity values (obtained from optical microscopy) between 0.78 and 1.00 for more than $50 \%$ of the particles.

For the case of Ti64, the composition of the main alloying elements ranged between 5.5 and $6.75 \mathrm{Al}, 3.5-4.5 \mathrm{~V}$ (see details in [33]). The average particle size was $36.8 \mu \mathrm{m}$, with the following particle size distribution: $\mathrm{D} 10=24.2 \mu \mathrm{m}$, $\mathrm{D} 50=35.8 \mu \mathrm{m}, \mathrm{D} 90=61.2 \mu \mathrm{m}$. Also, in this case, mostly spherical particles were observed, with circularity values between 0.85 and 1.00 for more than $50 \%$ of the particles.

The samples were manufactured on Renishaw AM250 and RenAM 500 systems for Ti6Al4V and Scalmalloy ${ }^{\circledR}$, respectively, under argon atmosphere. The layer thickness was set to $30 \mu \mathrm{m}$ in both cases. Samples were also thermally treated before extraction at $325^{\circ} \mathrm{C}$ during $4 \mathrm{~h}$ (annealing/aging) in air atmosphere followed by slow cooling for Scalmalloy ${ }^{\circledR}$, and at $730{ }^{\circ} \mathrm{C}$ during $1.5 \mathrm{~h}$ (annealing) in a vacuum with Argon atmosphere following by slow cooling.

Based on the used manufacturing process, the initial surface roughness $(\mathrm{Sa})$ was $21.20 \pm 2.85 \mu \mathrm{m}$ for Ti64 and $19.58 \pm 9.04 \mu \mathrm{m}$ for Scalmalloy ${ }^{\circledR}$. Prior to the laser smoothing process, the samples were cleaned with isopropanol to remove dirt particles. 


\subsection{Direct laser smoothing}

The laser experiments were realized using the direct laser writing (DLW) technology, which were performed on an industrial laser system (GF machining solutions P 600). The setup is illustrated in Fig. 1a. The DLW workstation uses a Ytterbium fiber laser source which emits light with a wavelength of $1064 \mathrm{~nm}$ with a maximal output power of $30 \mathrm{~W}$ depending on the pulse duration. The maximal available laser power decreases for shorter pulse durations at constant repetition rate. For instance, the maximal laser power at a frequency of $30 \mathrm{kHz}$ is approximately $30 \mathrm{~W}$ for a pulse duration of $200 \mathrm{~ns}, 14 \mathrm{~W}$ for $100 \mathrm{~ns}$ and $2.5 \mathrm{~W}$ for $8 \mathrm{~ns}$. The pulse duration can be set between 4 and $200 \mathrm{~ns}$. The laser beam was focused on the sample with an f-theta lens with a focal length of $254 \mathrm{~mm}$. This results in a working distance of approx. $280 \mathrm{~mm}$ from the laser head.

In this study, the highest laser power was used for all pulse durations. The laser fluence $F$ per pulse can be adjusted by changing the laser spot diameter at the irradiated region which is controlled by the working position. This methodology has been already used by Mai and Lim [34] as well as Chow et al. [25]. The focused laser beam has a spot diameter of approx. $70 \mu \mathrm{m}$, where the highest fluence level can be achieved. Three different working positions were utilized. The laser beam was scanned over the surface using a galvanometer scanner, with a maximal speed of $3.6 \mathrm{~m} / \mathrm{s}$. To achieve a homogenous smooth surface, two different scan strategies were examined. Parallel process strategy and $90^{\circ}$ rotated process strategy were considered as shown in Fig. 1b, c.

The number of scans for both process strategies were also examined and varied between 1 and 10 . The pulse overlap in $y$-direction and the hatch distance in $x$-direction were varied between 80 and $99 \%$. This can be calculated by the pulse separation distance and the laser spot diameter [35]. The pulse overlap was adjusted by constant triggering the laser pulses with $30 \mathrm{kHz}$ and changing the scan speed $(30 \mathrm{~mm} / \mathrm{s}$ up to $3600 \mathrm{~mm} / \mathrm{s})$. Using Eq. (1), it possible to calculate the laser fluence $(F)$ at the laser spot:

$F=\frac{P_{L}}{f A^{\prime}}$,

where $P_{L}$ is the average laser power, $f$ is the repetition rate (or frequency) and $A$ is the irradiated area. The parameters used in this study are summarized in Table 1.

For the smoothening test, matrices with areas of $2 \times 2 \mathrm{~mm}$ were processed for each parameter. All experiments were performed in air, at normal conditions of pressure and temperature.
Fig.1 a Setup of the DLW system used in the experiments which emits a laser beam with $1064 \mathrm{~nm}$ wavelength and a maximal power of $30 \mathrm{~W}$. The laser beam is guided over the substrate surface using a scanner; $\mathbf{b}, \mathbf{c}$ schematic drawing of the strategies used for treating the additive manufactured substrates. The circle represents a laser pulse and the red arrows represent the scan direction

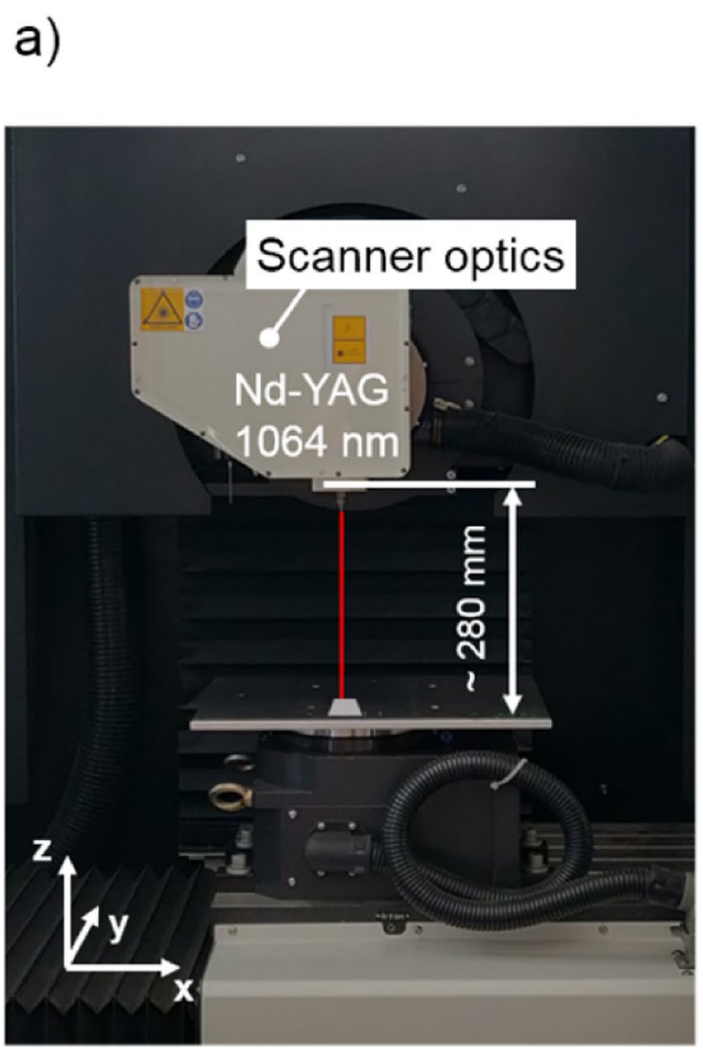

b) hatch distance

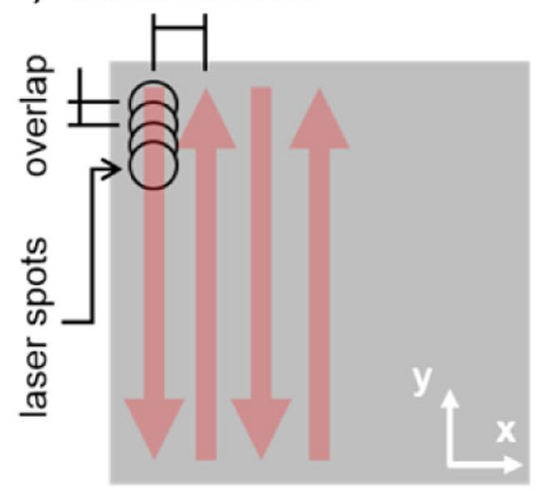

c)

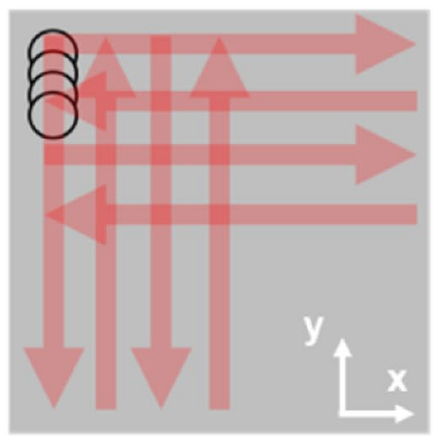


Table 1 Overview of selected parameters

\begin{tabular}{ll}
\hline Parameter & Value/range \\
\hline Laser fluence $\left(\mathrm{J} / \mathrm{cm}^{2}\right)$ & $0.57-24.0$ \\
Focus offset position $(\mathrm{mm})$ & $0.0,3.0,6.0$ \\
Frequency $(\mathrm{kHz})$ & 30 \\
Pulse duration $(\mathrm{ns})$ & $8,20,50,100,200$ \\
Overlap/hatch distance $(\%)$ & $0-99$ \\
Number of scans & $1-10$ \\
\hline
\end{tabular}

\subsection{Surface characterization}

For the examination of the morphology of the laser-treated surfaces, a confocal microscope (Sensofar S Neox) with $20 \times$ magnification was used. The roughness parameter $\mathrm{Sa}$ (arithmetical mean height), which is an extension of $R a$ to a surface, was measured according to ISO 25178. For statistical analyses, different positions in each treated are were measured. A Scanning Electron Microscope (ZEISS Supra $40 \mathrm{VP}$ ) was used to analyze the surface topology of the samples at an operating voltage of $5.0 \mathrm{kV}$.

\section{Results and discussion}

Using the infrared DLW setup, Ti64 and Scalmalloy ${ }^{\circledR}$ substrates were laser treated to examine the influence of the processing parameters on the surface roughness. Firstly, the effect of the pulse duration and the laser fluence were investigated, as shown in Effect of pulse duration and focus position on the surface roughness. The laser fluence was varied by changing the offset position of the DLW configuration. A second set of experiments was performed with the previously selected focus offset position and pulse duration for both materials. In this case, the influence of the pulse overlap, moving direction as well as the number of scans on the surface roughness were tested. These results are shown in Surface smoothing by changing of number of passes and moving directions. Finally, the ablation characteristic caused by the laser treatment process with the used ns-pulses is described in detail in Material removal due to the smoothing process.

\subsection{Effect of pulse duration and focus position on the surface roughness}

In the first set of experiments, the effect of the pulse duration and the amount of energy applied into the workpiece on the surface roughness were investigated. Three different focus positions were chosen to determine the spot diameter and, therefore, the energy which was applied to the material. Depending on the position where the beam interacts the
Table 2 Overview parameter screening set 1

\begin{tabular}{lcr}
\hline Focus position $(\mathrm{mm})$ & $\begin{array}{l}\text { Spot diameter } \\
(\mu \mathrm{m})\end{array}$ & Laser fluence $\left(\mathrm{J} / \mathrm{cm}^{2}\right)$ \\
\hline 0.0 & 70 & $2.1(8 \mathrm{~ns})-23.4(200 \mathrm{~ns})$ \\
3.0 (position 1) & 90 & $1.3(8 \mathrm{~ns})-14.1(200 \mathrm{~ns})$ \\
6.0 (position 2) & 135 & $0.5(8 \mathrm{~ns})-6.2(200 \mathrm{~ns})$ \\
\hline
\end{tabular}

surface, the laser can either heat, melt or ablate the material. The process strategy follows the approach described in detail by Chow et al. [25]. The laser fluence also depends on the pulse duration and was varied between 8 and $200 \mathrm{~ns}$. Shorter pulse durations are accompanied by smaller laser fluence. A summarized overview of the parameters used here is shown in Table 2.

Based on the state of the art, it is clear that the choice of parameters plays an important role in the quality of the final surface finish. In this regard, the change of $S a$, by varying the focus position between 0 and $6 \mathrm{~mm}$ as well as the pulse duration between 8 and $200 \mathrm{~ns}$, is shown in Fig. 2. As it can be observed, these parameters strongly influenced the surface topography depending on the material. For a better understanding of the effect of the laser processes on the surface roughness, the initial surface roughness is marked in green in Fig. 2, where the dashed lines denote the standard deviation. The large observed standard deviation for the reference surfaces can be explained by the quite irregular topography of these specimens. The obtained results show that the pulse duration is the most relevant parameter influencing the surface roughness, as it can be observed for Ti64 in Fig. $2 \mathrm{a}$ and for Scalmalloy ${ }^{\circledR}$ in Fig. 2 b.

The treatment of the Ti-alloy (Fig. 2a) follows a comparable scheme for all pulse durations depending on the focus positions. No significant variation in surface roughness was observed for pulse durations below $20 \mathrm{~ns}$. This suggests that the applied energy was insufficient and the material was only heated. By increasing the pulse duration, the surface roughness begins to decrease which can be explained by the higher applied energy into the material. As a result of the higher energy input, the material begins to melt and the initial high roughness peaks are reduced by re-melting. This phenomenon can be observed at all examined focus offset positions. By increasing the pulse duration up to $100 \mathrm{~ns}$, the roughness of the Ti64 samples could be significantly reduced. For example, the $S a$-value was reduced from 21.20 to $7.9 \mu \mathrm{m}$ when using the focus offset position 2. In general, it can be observed that a focus offset has a positive effect on the roughness which can be explained by the increased spot diameter and thus a decreased applied energy per area. A further increasing of the pulse duration to $200 \mathrm{~ns}$ leaded to an increase of the roughness, which indicates that the amount of energy introduced into the material was too high, 
Fig. 2 Surface roughness variation $(\mathrm{Sa})$ as function of the focus position and the pulse duration, for the additive manufactured Ti64 (a) and Scalmalloy ${ }^{\circledR}$ (b) samples. The experiments were performed with a laser wavelength of $1064 \mathrm{~nm}$ and a repetition rate of $30 \mathrm{kHz}$ a)

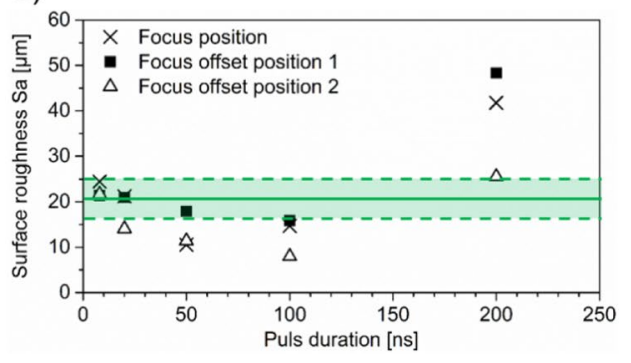

b)

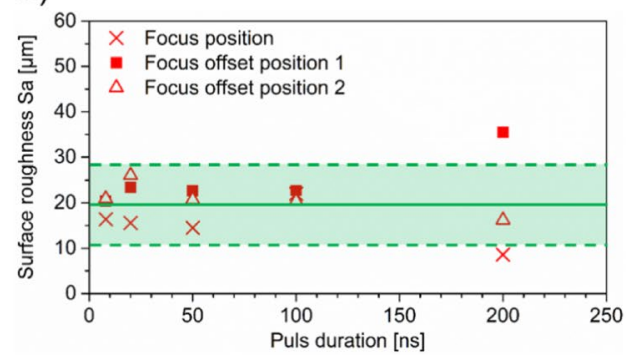

producing a larger volume of molten material and even starting an ablation process. For this pulse duration (200 ns), the strongest increase of the surface roughness was observed on the sample treated at the focus offset position 1. In this case, the surface roughness increases from 21.2 to $41.7 \mu \mathrm{m}$. In consequence, the optimal process condition for smoothing the surface of the titanium alloy was at a pulse duration of $100 \mathrm{~ns}$ and a focus offset position of $6.0 \mathrm{~mm}$, and were used for the rest of the experiments performed in this study.

A different behavior was observed for Scalmalloy ${ }^{\circledR}$. In this case, the effectiveness of the roughness reduction sing short pulse durations (up to $100 \mathrm{~ns}$ ) is low. As it can be seen in Fig. 2b, all measured surface roughness was in the range of the statistic standard deviation of the reference sample (from 10.5 to $28.6 \mu \mathrm{m}$ ). A positive effect on the surface roughness was only visible when longer pulses (200 ns) were used. This leads to the assumption that the thermal energy input was too low to sufficiently affect the material with pulse durations below $200 \mathrm{~ns}$. For instance, at the focus position, the surface roughness decreased from 19.6 to $8.6 \mu \mathrm{m}$. This suggests that the complete irradiated area was remelted using the focused beam. As a result, the molten material flows into the valleys and reduces the roughness. However, for the focus offset position 2, the roughness was not affected, while at the focus position 1, the surface roughness increased to $38.4 \mu \mathrm{m}$. This effect can be explained due to the fact, that the thermal applied energy was too low at the focus offset position 2 to affect the material. The material was neither ablated nor remelted. When using the focus offset position 1, the thermal energy introduced into the material was higher, which resulted in more molten material. Nevertheless, the applied energy was not sufficient to remelt the roughness peaks and thus reduce the roughness. It also seems, that the valleys of the material were affected by the laser and created material craters. The created craters and the initial roughness peaks had a negative effect on the roughness, which resulted in an increase in the roughness value. The optimal parameters in these experiments for Scalmalloy ${ }^{\circledR}$ were at a pulse duration of $200 \mathrm{~ns}$ and the focused laser spot, without offset $(0.0 \mathrm{~mm})$.

In summary, the first experiments performed have shown that laser pulses with longer durations are more effective for reducing surface roughness: $100 \mathrm{~ns}$ and $200 \mathrm{~ns}$ for Ti64 and Scalmalloy ${ }^{\circledR}$, respectively. Based on these results, the abovementioned pulse durations were used in the rest of this study.

\subsection{Surface smoothing by changing of number of passes and moving directions}

After the preliminary laser treatment experiments described in 3.1, a second set of experiments was performed. In this case, a large number of parameter variations were realized to find a correlation between the pulse-to-pulse overlap $(\mathrm{OV}=80-99 \%)$ and the scanning strategy (parallel and $90^{\circ}$ rotated, see Fig. 1) with the aim of reducing the surface roughness.

Figure 3 shows representative 3D images of the surface topography of both materials depending on the pulse overlap (OV). The surface topography images for the Ti64 (a-c) and Scalmalloy ${ }^{\circledR}(\mathrm{d}-\mathrm{f})$ samples provide evidence that the surface roughness can be significantly influenced by the laser process. In all cases, 10 passes were used. The confocal microscope images of Fig. 3 show that, for example, for a pulse overlap of $99 \%$ a very rough topography is obtained in both materials, which can be explained by the large amount of produced molten material due to the very high cumulated energy density (see Fig. 3a, d). In contrast, when the pulse overlap was lower, the amount of the molten material reduced and different surface conditions, depending on the material were observed, as shown in Fig. 3b, c, e-f.

Further evaluations were done to quantify the effects in detail. The measured results in terms of varying pulse-topulse distance and the movement strategy are summarized in Fig. 4a, b for Ti64 and in Fig. 4c, d for Scalmalloy ${ }^{\circledR}$. The measured surface roughness, or arithmetical mean height $\mathrm{Sa}$, illustrates the strong effect of the laser treatment. As it can be seen in the figure, the highest pulse overlap (99\%) led to the highest surface roughness (see confocal images in Fig. 3a, $d$ for both materials). In this case, the amount of molten material strongly increased due to the high pulse overlap and thus the high amount of cumulated energy. This effect was observed for all number of performed scans (passes). 


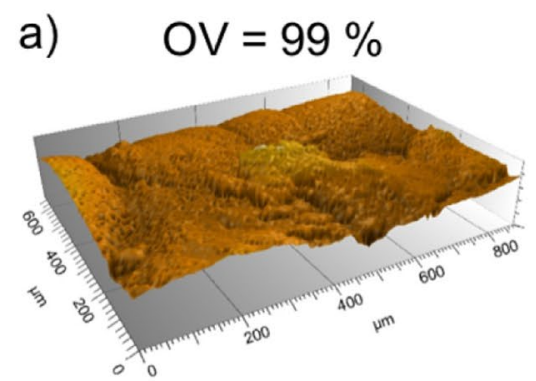

d)

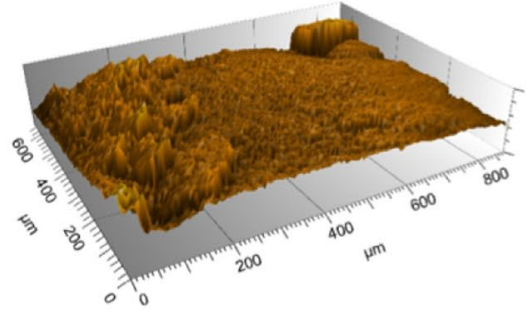

b) $\quad O V=95 \%$

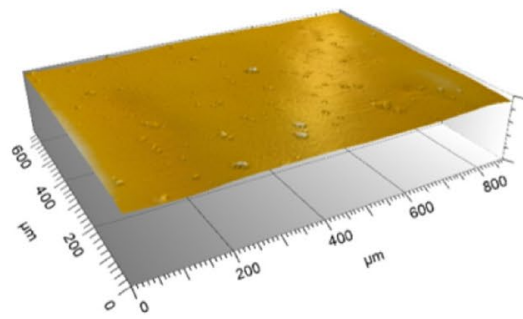

e)

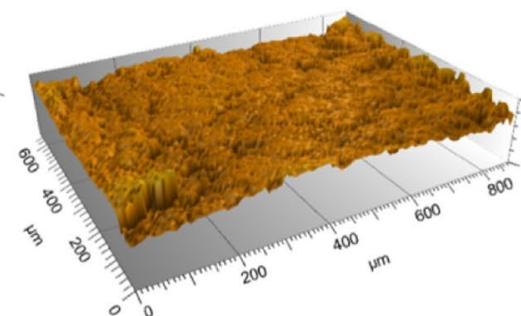

c) $\quad \mathrm{OV}=90 \%$

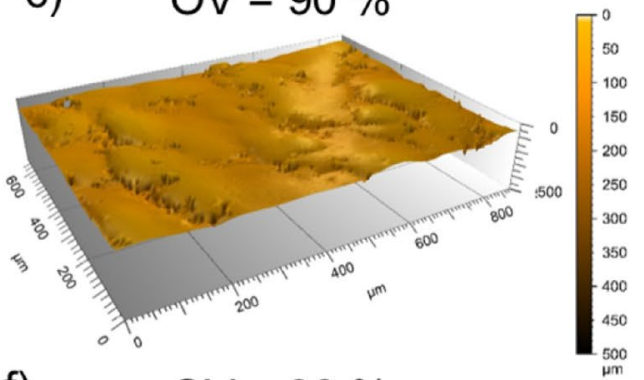

f)

$\mathrm{OV}=80 \%$

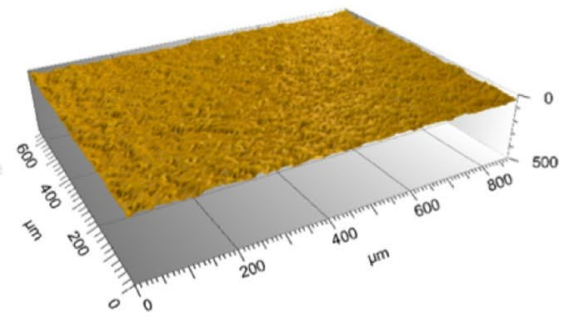

Fig. 3 Confocal microscope images of the laser-treated surface of Ti64 (a-c) and Scalmalloy ${ }^{\circledR}(\mathbf{d}-\mathbf{f})$ for different pulse-to-pulse feeds and 10 passes

Fig. 4 Surface roughness $(\mathrm{Sa})$ of the laser-treated surfaces using different overlaps (OV) and number of passes. The diagrams illustrate the obtained results for Ti64 (a, b) and Scalmalloy ${ }^{\circledR}(\mathbf{c}, \mathbf{d})$. The used scanning strategy is indicated in the image: parallel $(\mathbf{a}, \mathbf{c})$ and rotated $(\mathbf{b}, \mathbf{d})$ strategies a)

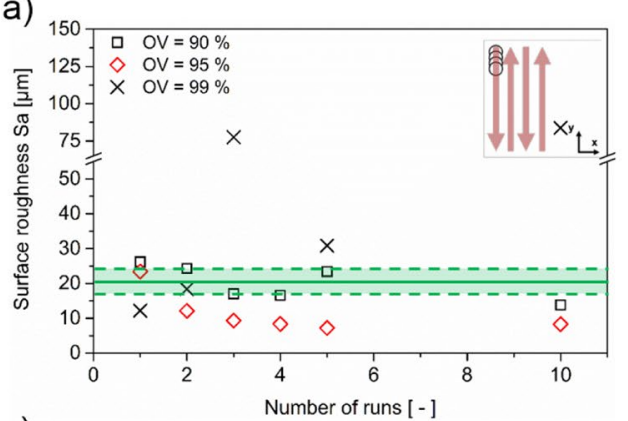

c)

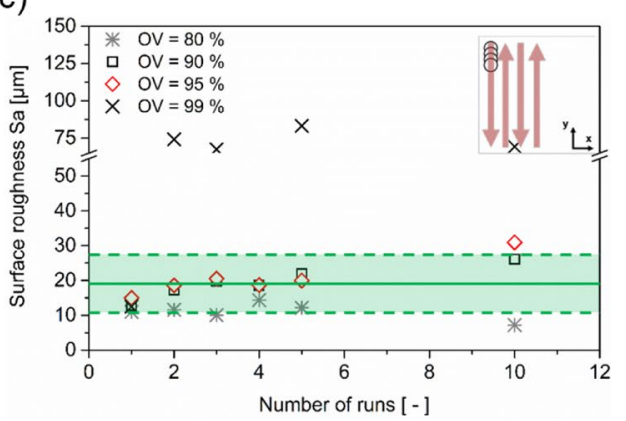

b)

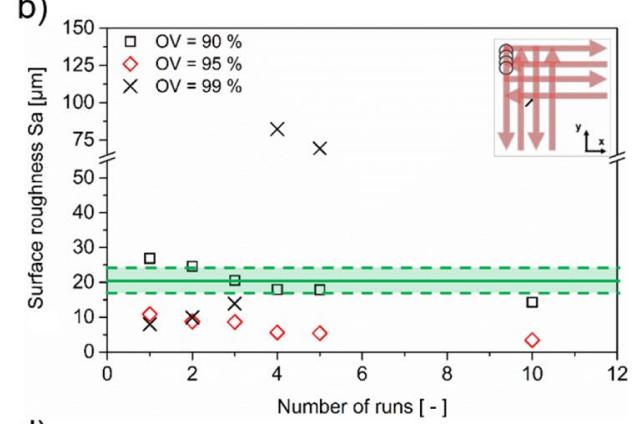

d)

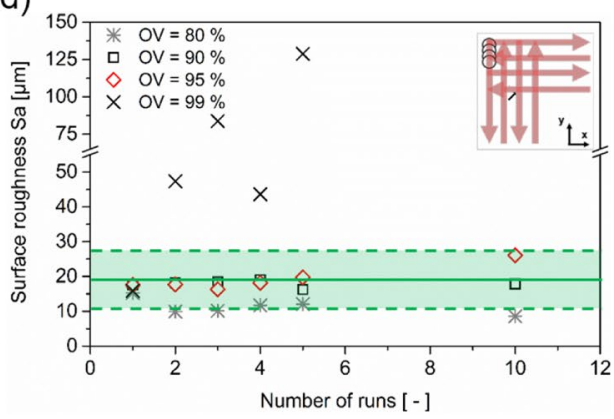

A different behavior was observed for smaller pulse overlaps. In this case, the effectiveness of roughness reduction using pulse overlaps between 80 and $95 \%$ was higher. As it can be seen in Fig. 4, many measured roughness values were below the statistical standard deviation of the reference samples. In particular, the surface roughness strongly decreased with the number of passes and the lowest value was achieved after 10 passes.
Clearly, the most important observation is that both materials can be smoothed, but with different parameters. In case of Ti64, the best results were obtained at $100 \mathrm{~ns}$ (as explained in the previous section) and a laser fluence of $3.1 \mathrm{~J} / \mathrm{cm}^{2}$. Differently, for Scalmalloy ${ }^{\circledR}$, the optimal conditions were with $200 \mathrm{~ns}$ pulses and a significantly higher laser fluence of $23.4 \mathrm{~J} / \mathrm{cm}^{2}$. These noticeable differences can be attributed to the different optical and thermal properties of 
the used materials, such as the reflection and thermal conductivity. For example, the reflectivity at normal incidence $\mathrm{R}$ $(\varphi=0)$ is approximately 0.55 for pure titanium and 0.95 for pure aluminum in the near-infrared region [36]. Due to the higher reflection and thus less absorption of the aluminum alloy $\left(\right.$ Scalmalloy $\left.{ }^{\circledR}\right)$, more energy per unit of area is required to treat the material. In addition, the higher thermal conductivity for Scalmalloy ${ }^{\circledR}$ is responsible for a longer thermal diffusion length and thus higher fluences are needed to reach higher temperatures at the material surface.

From Fig. 4a, b, it can be also seen that in case of Ti64, the smoothest surface was achieved using a pulse overlap of $95 \%$. Based on the surface topography analysis, it was found that in case of lower pulse overlaps $(90 \%)$ and number of passes, the surface roughness was just marginally affected by the laser treatment. An important effect on the roughness reduction was only visible after 10 passes. In this case, the surface roughness was decreased from 21.20 to $14.20 \mu \mathrm{m}$, using the strategy "parallel" (10 passes and 90\% Overlap). This means that each laser scan partially remelted the material surface, contributing positively to the reduction of the surface roughness.

Further improvements were observed for a pulse to pulse overlap of $95 \%$. In this case, the roughness decreases continuously as function of the number of passes. This leads to the assumption that due to the higher cumulated energy, a continuous smoothing process takes place since more material peaks were remelted with each pass. The average surface roughness for the mentioned overlap after 10 passes was $7.22 \pm 2.31 \mu \mathrm{m}$ and $3.45 \pm 1.30 \mu \mathrm{m}$ for both strategies used, being parallel (Fig. 4a) and rotated (Fig. 4b), respectively. In consequence, the smoothest surface was obtained with a pulse overlap of $95 \%$ and 10 passes with rotated scanning strategy, which means a reduction of $84 \%$ of the initial surface roughness.

As indicated before, any positive effect could be observed by further increasing the pulse overlap (e.g., 99\%). In this case, these high overlaps significantly increased the cumulated energy and in consequence, a significant of material can be molten or ablated (note that $95 \%$ overlap denotes that 20 pulses reached the same positions while for $99 \%$, 100 pulses provide the laser energy to the material surface).

In contrast, in the case of Scalmalloy ${ }^{\circledR}$, different processing conditions were found to be more satisfactory for reducing the surface roughness. First of all, the standard deviation of the initial surface roughness of Scalmalloy ${ }^{\circledR}$ was significantly higher compared to Ti64, as can be seen in Fig. 4c, d (see green area). As mentioned before, using a pulse overlap of $99 \%$ resulted in a strong increase in the roughness. This is an indication that the surface was strongly affected by the laser process. The higher pulse overlap results in a larger amount of molten material and even in local material ablation, which leads to additional surface features on the surface. Similarly, to Ti64, when using pulse overlaps of $90 \%$ and $95 \%$, any significant variation on the roughness was observed since all evaluated conditions are in the range of standard deviation of the initial surface roughness. However, the lowest surface roughness for both used strategies was achieved when using $80 \%$ of pulse overlaps, which means that at $90 \%$ and $95 \%$ the laser process is also modifying the Scalmalloy ${ }^{\circledR}$ surface. This leads to the assumption that the material was mainly heated and sparsely melted or ablated. Furthermore, by increasing the number of passes (up to 10 runs) and a pulse overlap of $90 \%$ or $95 \%$ an increase in surface roughness was observed, which leads to the assumption that not only the roughness peaks were remelted, but also that material was ablated and melt bulges were created. For a pulse overlap of $80 \%$, the surface roughness was reduced by increasing the number of passes up to 10 . In the last case, the measured surface roughness was significantly lower than the initial roughness. The average surface roughness after 10 runs for both scanning strategies was $6.84 \pm 3.73 \mu \mathrm{m}$ (Fig. 4c) and $8.60 \pm 3.58 \mu \mathrm{m}$ (Fig. 4d), respectively.

To closer examine the difference between the initial surface and the treated surface, SEM images of both states and materials were considered. The images of the initial and selected laser-treated surface are shown in Fig. 5. The results of the laser-treated samples with 10 scans show the best outcomes, as it was explained above. Comparing the original surface (Fig. 5a, c) and the treated surface (b, d), it is clear that the laser process has strongly modified the surface of both materials. As it can be observed, the untreated surfaces are characterized by drop-shaped roughness peaks, which is typical of non-treated surfaces in the as-manufactured condition. They have the largest roughness levels mainly caused by the partially melted powder particles attached to the surfaces. In contrast, the topography of the treated surfaces is very different. In the case of Ti64 (Fig. 5a, b), it is visible that the treated surface shows a very flat and homogeneous surface topography. In addition, very few melt drops with sizes below $2-5 \mu \mathrm{m}$ are observed. In the case of Scalmalloy ${ }^{\circledR}$, it is also visible that large droplets in the untreated material were removed (Fig. 5c), but the final surface topography (Fig. 5d) is quite different compared to Ti64. A probable explanation for the observed topography can be related to nanoparticles and clusters of molten metal that are deposited from the ablation cloud, which were formed during the ns laser process. Such an effect has been already observed in other aluminum-based alloys as described by Boinovich et al. [37]. Furthermore, also other processes take place during multi-pulse laser treatment, such as high-temperature interactions between the melted surface layers and droplets of molten material as well as its suboxides in the laser ablation plume which could favor the formation of this topography. 
Fig. 5 SEM images show the effectiveness of the laser smoothing process for Ti64 $(\mathbf{a}, \mathbf{b})$ and Scalmalloy ${ }^{\circledR}(\mathbf{c}, \mathbf{d})$. Images $(\mathbf{a}, \mathbf{c})$ show the initial surface and images $(\mathbf{b}, \mathbf{d})$ the laser smoothed surface
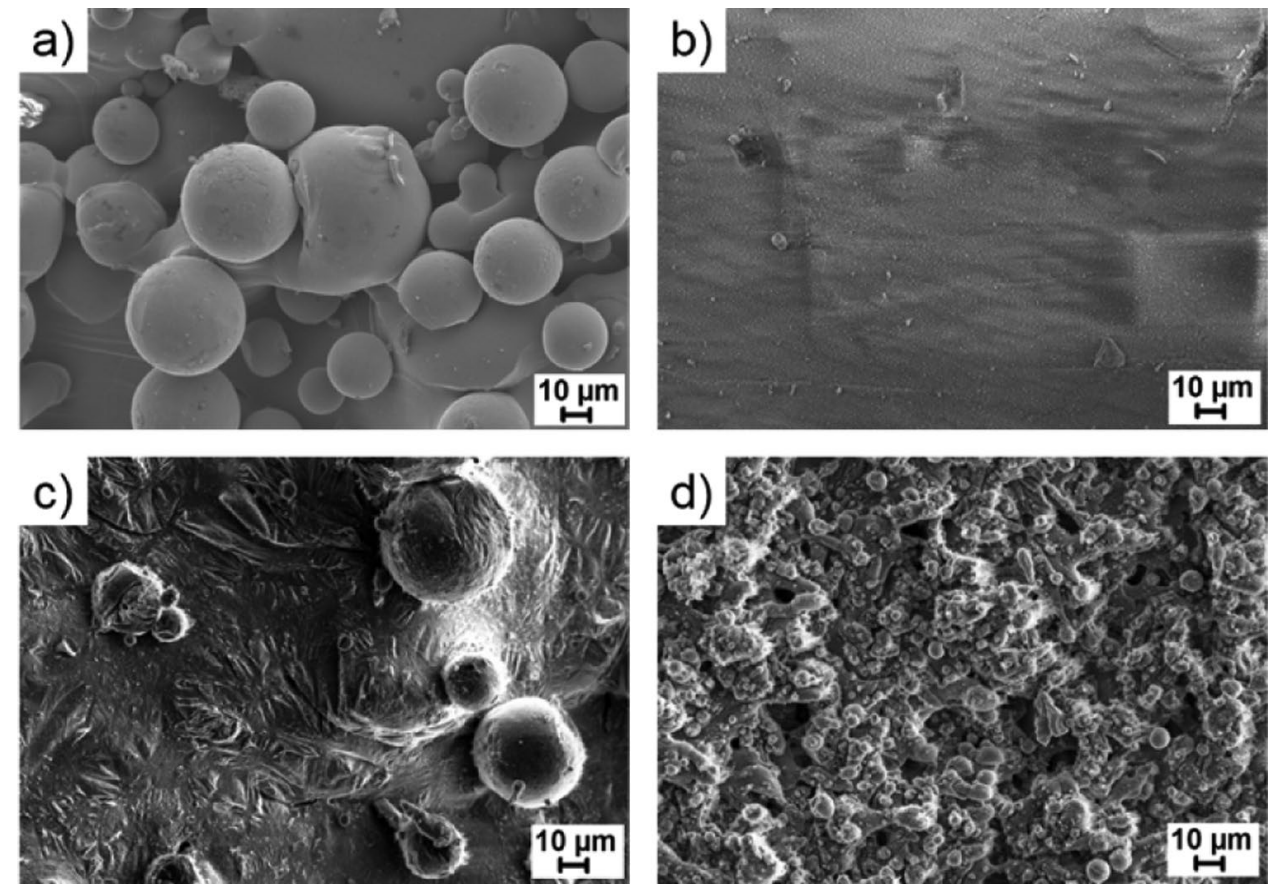

Based on the experimental data presented before, several statements can be made about adjusting laser parameters and the general laser smoothing process. Firstly, it is clear that the surface quality, in terms of reducing the mean roughens $S a$, can be achieved by adjusting the pulse-to-pulse overlap. The results also indicate that several passes of the laser beam over the same area can have a positive effect on surface flattening if the correct overlap is used. Thus, in general, it can be said, that it is more effective to work with a lower pulse overlap but more laser scan runs. A further observation is that the surface roughness was not significantly influenced by the scan strategy. In addition, it has to be mentioned that the standard deviation of the surface roughness after the laser process is significantly lower than the deviation of the initial surface roughness, which was observed for both materials. This means that the roughness peaks have been remelted and that the surface was leveled.

\subsection{Material removal due to the smoothing process}

After evaluating and defining the most relevant processing parameters for the smoothing process of the different materials, the surface levels of the untreated and treated areas were measured (ablation depth). A graphical representation of the increasing ablation depth due to the number of passes is shown in Fig. 6a. To quantify the ablation depth, the height difference of the untreated and laser-treated area was measured. An example is shown in Fig. $6 \mathrm{~b}$ for Ti64 treated with an overlap of $95 \%$ and 10 passes.

From Fig. 6a, it can be seen that the ablation depth is relatively small for one or two laser scans $(<2.5 \mu \mathrm{m})$. However, a significant increase in the depth can be observed for more than two passes. The increased ablation depth is clearly related to the cumulated applied energy due to the repeated passes. Thus, these results indicate that the material was not
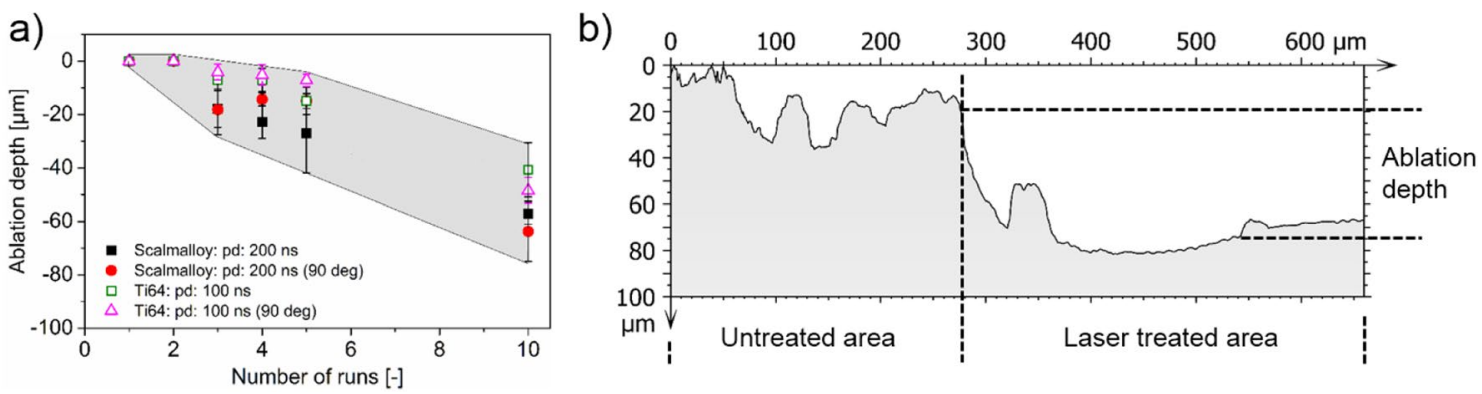

Fig. 6 a Material removal as a function of the number of passes through the laser smoothing process; $\mathbf{b}$ the profile of the transitional area between the untreated and the laser-treated area 
only melted but also ablated. The maximum obtained ablation depths were $44.6 \pm 7.5 \mu \mathrm{m}$ for Ti64 and $60.4 \pm 7.6 \mu \mathrm{m}$ for Scalmalloy ${ }^{\circledR}$. These ablation depths were produced after 10 passes and pulse durations of $100 \mathrm{~ns}$ and $200 \mathrm{~ns}$, respectively. This effect is nearly independent of the movement strategy, as mentioned in the previous section. In general, it can be said that the ablation depth is slightly higher for Scalmalloy ${ }^{\circledR}$ than for Ti64 and can be attributed to the higher laser fluence used $\left(3.1 \mathrm{~J} / \mathrm{cm}^{2}\right.$ and $23.4 \mathrm{~J} / \mathrm{cm}^{2}$ for Ti64 and Scalmalloy ${ }^{\circledR}$, respectively). In consequence, the material removal due to the laser smoothing process has to be considered in the design of the 3D part to match the required dimensions.

\section{Summary and conclusions}

In this study, experimental research was carried out to better understanding the smoothing process of additive manufactured components of Ti64 and Scalmalloy ${ }^{\circledR}$ using ns-laser pulses. The following most relevant findings can be drawn from this work:

(i) First, it was demonstrated the capability of nanosecond pulses for reducing the surface roughness of additive manufactured Ti64 and Scalmalloy ${ }^{\circledR}$ alloys.

(ii) The reached surface roughness significantly depended on the material and the used parameter such as applied fluence, pulse duration, pulse-to-pulse overlap and number of passes.

(iii) The laser treatments permitted the reduction of the surface roughness from $21.20 \pm 2.85 \mu \mathrm{m}$ to $3.45 \pm 1.3 \mu \mathrm{m}$ for Ti64 and from $19.58 \pm 9.04 \mu \mathrm{m}$ to $6.84 \mu \mathrm{m} \pm 3.73$ for Scalmalloy ${ }^{\circledR}$, which corresponds to $84 \%$ and $65 \%$, respectively.

(iv) It was also shown that not only the roughness can be reduced, but also its standard deviation (by more of 50\%) which means that the larger particles are molten or ablated. This lead to a more homogeneous surface topography and could consequently increase the mechanical performance.

(v) It was observed that the pulsed laser treatment method is partially ablating the used materials, and that the ablation depth strongly depends on the number of passes. In consequence, the material removal due to the laser smoothing process has to be considered in the design of the 3D part

In future investigations, the effect of laser polishing on the alloy fatigue life will be explored, assessing also the microstructural differences of the heat-affected zone in comparison with the bulk material.
Funding Open Access funding enabled and organized by Projekt DEAL. This research and development project is funded by the German Federal Ministry of Education and Research (BMBF) within the Innovations for Tomorrow's Production, Services, and Work (02P18E010 02P18E012) and implemented by the Project Management Agency Karlsruhe (PTKA). CATEC would like to acknowledge the CDTI and the Spanish Ministry of Science and Innovation for the funding received for the CEFAM Project under the Awarding and funding program for Excellent Technology Centers 'Cervera' (CER 20191005). The author is responsible for the content of this publication.

\section{Compliance with ethical standards}

Conflict of interest On behalf of all authors, the corresponding author states that there is no conflict of interest.

Open Access This article is licensed under a Creative Commons Attribution 4.0 International License, which permits use, sharing, adaptation, distribution and reproduction in any medium or format, as long as you give appropriate credit to the original author(s) and the source, provide a link to the Creative Commons licence, and indicate if changes were made. The images or other third party material in this article are included in the article's Creative Commons licence, unless indicated otherwise in a credit line to the material. If material is not included in the article's Creative Commons licence and your intended use is not permitted by statutory regulation or exceeds the permitted use, you will need to obtain permission directly from the copyright holder. To view a copy of this licence, visit http://creativecommons.org/licenses/by/4.0/.

\section{References}

1. Awd M, Tenkamp J, Hirtler M, Siddique S, Bambach M, Walther $\mathrm{F}$ (2018) Comparison of microstructure and mechanical properties of scalmalloy ${ }^{\circledR}$ produced by selective laser melting and laser metal deposition. Materials. https://doi.org/10.3390/ma11010017

2. Liu S, Shin YC (2019) Additive manufacturing of Ti6Al4V alloy: a review. Mater Des 164:107552. https://doi.org/10.1016/j.matde s.2018.107552

3. Gibson I, Rosen DW, Strucker B (2009) Additive manufacturing technologies, 2nd edn. Springer, New York

4. Bagehorn S, Wehr J, Maier HJ (2017) Application of mechanical surface finishing processes for roughness reduction and fatigue improvement of additively manufactured Ti-6Al-4V parts. Int J Fatigue 102:135-142. https://doi.org/10.1016/j.ijfat igue.2017.05.008

5. Sakar S, Kumar CS, Nath AK (2019) Effects of different surface modifications on the fatigue life of selective laser melted 15-5 PH stainless steel. Mater Sci Eng A 762:1-9. https://doi. org/10.1016/j.msea.2019.138109

6. Yu H, Li F, Wang Z, Zeng X (2018) Fatigue performances of selective laser melted Ti-6Al-4V alloy: Influence of surface finishing, hot isostatic pressing and heat treatments. Int J Fatigue 120:175-183. https://doi.org/10.1016/j.ijfatigue.2018.11.019

7. Spierings AB, Starr TL, Wegener K (2013) Fatigue performance of additive manufactured metallic parts. Rapid Prototyp J. https ://doi.org/10.1108/13552541311302932

8. Novovic D, Dewes RC, Aspinwall DK, Voice W, Bowen P (2004) The effect of machined topography and integrity on fatigue life. Int J Mach Tools Manuf 44:125-134. https://doi.org/10.1016/j. ijmachtools.2003.10.018

9. Peguas J, Roach M, Williamson RS, Shamsaei N (2018) Surface roughness effects on the fatigue strength of additively 
manufactured Ti-6Al-4V. Int J Fatigue 116:543-552. https://doi. org/10.1016/j.ijfatigue.2018.07.013

10. Denti L, Bassoli E, Gatto A, Santecchia E, Mengucci P (2019) Fatigue life and microstructure of additive manufactured Ti6A14V after different finishing processes. Mater Sci Eng A 755:1-9. https ://doi.org/10.1016/j.msea.2019.03.119

11. Li Y, Wu Y, Zhou L, Fujimoto M (2014) Vibration-assisted dry polishing of fused silica using a fixed-abrasive polisher. Int $\mathrm{J}$ Mach Tools Manuf 77:93-102. https://doi.org/10.1016/j.ijmac htools.2013.10.005

12. Bagherifard S, Beretta N, Monti S, Riccio M, Bandini M, Guagliano M (2018) On the fatigue strength enhancement of additive manufactured AlSi10Mg parts by mechanical and thermal postprocessing. Mater Des 145:28-41. https://doi.org/10.1016/j.matde s.2018.02.055

13. Critchlow GW, Brewis DM (1995) Review of surface pretreatments for titanium alloys. Int J Adhes Adhes 15:161-172. https:// doi.org/10.1016/0143-7496(95)91627-I

14. Gupta K (2018) Micro and precision manufacturing. Springer Nature. https://doi.org/10.1007/978-3-319-68801-5

15. Poprawe R (2011) Tailored light 2. Springer, Berlin Heidelberg

16. Ma CP, Guan YC, Zhou W (2017) Laser polishing of additive manufactured Ti alloys. Opt Lasers Eng 93:171-177. https://doi. org/10.1016/j.optlaseng.2017.02.005

17. Bordatchev E, Cvijanovic S, Tutunea-Fatan OR (2019) Effect of initial surface topography during laser polishing process: statistical analysis. Procedia Manuf 34:269-274. https://doi. org/10.1016/j.promfg.2019.06.150

18. Temmler A, Liu D, Preußner J, Oeser S, Luo J, Poprawe R, Schleifenbaum JH (2020) Influence of laser polishing on surface roughness and microstructural properties of the remelted surface boundary layer of tool steel H11. Mater Des 192:108689. https:// doi.org/10.1016/j.matdes.2020.108689

19. Malinauskas M, Žukauskas A, Hasegawa S, Hayasaki Y, Mizeikis V, Buividas R, Juodkazis S (2016) Ultrafast laser processing of materials: from science to industry. Light Sci Appl 5:e16133. https://doi.org/10.1038/lsa.2016.133

20. Yuan JL, Zhao P, Ruan J, Cao ZX, Zhau WH, Xing T (2003) Lapping and polishing process for obtaining super-smooth surfaces of quartz crystal. J Mater Process Technol 138:116-119. https://doi. org/10.1016/S0924-0136(03)00058-X

21. Nüsser C, Kumstel J, Kiedrowski T, Diatlov A, Willenborg E (2015) Process- and material-induced surface structures during laser polishing. Adv Eng Mater 17(3):268-277. https://doi. org/10.1002/adem.201400426

22. Lambarri J, Leunda J, Soriano C, Sanz C (2013) Laser surface smoothing of nickel-based superalloys. Phys Procedia 41:255265. https://doi.org/10.1016/j.phpro.2013.03.077

23. Marimuthu S, Triantaphyllou A, Antar M, Wimpenny D, Morton H, Beard M (2015) Laser polishing of selective laser melted components. Int J Mach Tools Manuf 95:97-104. https://doi. org/10.1016/j.ijmachtools.2015.05.002
24. Perry TL, Werschmoeller D, Li X, Pfefferkorn FE, Duffie NA (2009) Pulsed laser polishing of micro-milled Ti6Al4V samples. J Manuf Process 11:74-81. https://doi.org/10.1016/j.jmapr o.2009.10.001

25. Chow MTC, Bordatchev EV, Knopf GK (2013) Experimental study on the effect of varying focal offset distance on laser micropolished surfaces. Int J Adv Manuf Tech 67:2607-2617. https://doi.org/10.1007/s00170-012-4677-z

26. Willenborg E, Wissenbach K, Poprawe R (2003) Polishing by Laser Radiation. Proc. of the 2nd International WLT-Conference on Lasers in Manufacturing, pp. 297-300

27. Heidrich S, Weingarten C, Willenborg E, Poprawe R (2014) Polishing and form correction with laser radiation. Classical Optics OTu1B4. https://doi.org/10.1364/OFT.2014.OTu1B.4

28. Weingarten C, Schmickler A, Willenborg E, Wissenbach K, Poprawe R (2017) Laser polishing and laser shape correction of optical glass. J Laser Appl 29:011702. https://doi. org/10.2351/1.4974905

29. Burzic B, Hofele M, Mürdter S, Riegel H (2017) Laser polishing of ground aluminum surfaces with high energy continuous wave laser. J Laser Appl 29:011701. https://doi.org/10.2351/1.4966923

30. Nüsser C, Sändker H, Willenborg E (2013) Pulsed laser micro polishing of metals using dual-beam technology. Phys Procedia 41:346-355. https://doi.org/10.1016/j.phpro.2013.03.087

31. Spierings AB, Dawson K, Kern K, Palm F, Wegener K (2017) SLM-processed Sc- and Zr- modified Al-Mg alloy: mechanical properties and microstructural effects of heat treatment. Mat Sci Eng A 701:264-273. https://doi.org/10.1016/j.msea.2017.06.089

32. Froes F, Boyer R, Dutta B (2019) Introduction to aerospace materials requirements and the role of additive manufacturing. Addit Manuf Aerosp Ind. https://doi.org/10.1016/B978-0-12-81406 2-8.00001-7

33. Renishaw plc (2017) Data sheet: Ti6Al4V ELI-0406 powder for additive manufacturing. http://resources.renishaw.com/en/downl oad/data-sheet-ti6al4v-eli-0406-powder-for-additive-manufactur ing--94700. Accessed 09 November 2020

34. Mai TA, Lim GC (2014) Micromelting and its effects on surface topography and properties in laser polishing of stainless steel. J Laser Appl 16:221-228. https://doi.org/10.2351/1.1809637

35. Aguilar-Morales AI, Alamri S, Kunze T, Lasagni AF (2018) Influence of processing parameters on surface texture homogeneity using Direct Laser Interference Patterning. Opt Laser Technol 107:216-227. https://doi.org/10.1016/j.optlastec.2018.05.044

36. Weaver JH, Frederiksen HPR (2001) Optical properties of selected elements. CRC handbook of chemistry and physics. CRC Press Inc, Florida

37. Boinovich LB, Modin EB, Sayfutdinova AR, Emelyanenko KA, Vasiliev AL, Emelyanenko AM (2017) Combination of functional nanoengineering and nanosecond laser texturing for design of superhydrophobic aluminum alloy with exceptional mechanical and chemical properties. ACS Nano 11:10113-10123. https://doi. org/10.1021/acsnano.7b04634 